\title{
Configurações
}

Revista de sociologia

\section{Género e tecnologias da informação e da comunicação no espaço doméstico: não chega ter, é preciso saber, querer e poder usar}

Technologies of information and communication in the domestic space: it is not enough to have, you need to know, to want and be able to use Genre et technologies de l'information et de la communication dans l'espace domestique : il ne suffit pas d'avoir, il faut aussi savoir, vouloir et pouvoir utiliser

\section{Maria João Simões, Soledad Las Heras e Amélia Augusto}

\section{OpenEdition}

Journals

\section{Edição electrónica}

URL: http://journals.openedition.org/configuracoes/831

DOI: 10.4000/configuracoes.831

ISSN: 2182-7419

\section{Editora}

Centro de Investigação em Ciências Sociais

Edição impressa

Data de publição: 5 Fevereiro 2011

Paginação: 155-172

ISSN: 1646-5075

\section{Refêrencia eletrónica}

Maria João Simões, Soledad Las Heras e Amélia Augusto, « Género e tecnologias da informação e da comunicação no espaço doméstico: não chega ter, é preciso saber, querer e poder usar », Configurações [Online], 8| 2011, posto online no dia 21 fevereiro 2013, consultado o 30 abril 2019. URL : http://journals.openedition.org/configuracoes/831; DOI : 10.4000/configuracoes.831 


\section{Género e tecnologias da informação e da comunicação no espaço doméstico: não chega ter, é preciso saber, querer e poder usar}

Technologies of information and communication in the domestic space: it is not enough to have, you need to know, to want and be able to use

Genre et technologies de l'information et de la communication dans l'espace domestique : il ne suffit pas d'avoir, il faut aussi savoir, vouloir et pouvoir utiliser

Maria João Simões, Soledad Las Heras e Amélia Augusto

\section{Introdução}

1 Temos assistido a alterações, algumas delas relevantes no âmbito das relações de género, quer na família, quer no trabalho. A diferenciação de papéis entre homens e mulheres no emprego reduziu-se de modo significativo, e algumas mudanças podem também ser constatadas na esfera doméstica: os homens ajudam mais nas tarefas e no cuidado a prestar aos filhos (Sayer, 2005; Fisher et al., 2006). Mas as mulheres continuam a

suportar um desproporcionado fardo de responsabilidades no seio familiar; elas trabalham muito mais em casa, e quando ao tempo gasto nessas actividades se soma o tempo gasto no emprego, percebemos que muitas mulheres casadas têm muito menos tempo livre do que os seus maridos. (Wright, 2008: 311)

A partir de alguns resultados de um projecto em curso denominado "Tempo e tecnologia: uma abordagem de género para o contexto português", o presente artigo procura descortinar e analisar as complexas relações que se dão no âmbito do espaço doméstico entre, por um lado, o acesso às tecnologias da informação (TI), às tecnologias de comunicação (TC) e às tecnologias de informação e comunicação (TIC) e, por outro, os 
padrões e as representações tradicionais de género, os quais contribuem para o carácter genderizado dessas tecnologias; desvendam-se, ainda, modos como as referidas tecnologias condicionam a acção social.

Num primeiro ponto, apresentam-se, de modo sintético, as teorias em presença sobre a mudança tecnológica e a mudança social, identificando aquela que as autoras consideraram ter maior valor heurístico para conduzir a investigação. Analisando a questão do acesso às TIC, discute-se a operacionalização que por vezes se faz desse conceito, a qual tende a obscurecer formas mais diversificadas de desigualdade social que se registam no âmbito das diversas dimensões do acesso. A reflexão centra-se nas TIC, dadas as especificidades que desde sempre estiveram associadas ao seu acesso. Contudo, com a fusão de funções a que se tem assistido nas várias TI e também nas TC, especialmente nas suas últimas gerações, vão-se colocando também a ambas tipos de barreiras ao acesso similares às que originalmente se colocavam apenas às TIC. Ainda neste primeiro ponto, discute-se o espaço doméstico, enquanto espaço de socialização e privacidade, assim como se documenta a crescente tecnificação do lar e se enunciam algumas das suas consequências.

No ponto dois apresentam-se e justificam-se as opções metodológicas que guiaram a investigação.

5 Nos pontos três e quatro, a partir da análise e da discussão dos dados, explora-se a diferença nas várias dimensões do acesso às TC, TI e TIC entre homens e mulheres no espaço doméstico, considerando-se particularmente a influência exercida pelos papéis de género.

\section{Tecnologias e género no espaço doméstico: o caso das TI, TC e TIC}

\subsection{A tecnologia como um processo social}

6 Face à diversidade de perspectivas teóricas sobre a mudança social e tecnológica, que colocam inevitavelmente perguntas diferentes à realidade em estudo, importa explicitar que perspectiva se considerou ter maior valor heurístico para esta investigação, apresentando-se, não obstante e de modo sucinto, o porquê da não-adopção de outras perspectivas teóricas.

7 A perspectiva mais difundida, e quase hegemónica nas ciências sociais até finais de 1970, mas mesmo assim ainda hoje muito adoptada e dominante ao nível das políticas públicas, é o determinismo tecnológico, no qual a tecnologia tem sido tratada como se existisse acima da sociedade e determinasse a sua forma, partindo-se, pois, do pressuposto de que o desenvolvimento tecnológico tem efeitos sociais preestabelecidos e universais (Fischer, 1985; Lyon, 1992; Simões, 2005, 2006). Um tal efeito ocorreria com independência das estruturas sociais de desigualdade, nomeadamente o género.

8 Quando se passa para os estudos em que há uma relação de determinação no sentido inverso, ou seja, da sociedade em relação à tecnologia, entra-se na perspectiva essencialista de sinal contrário: o determinismo social estruturalista.

9 A tecnologia passa de variável independente a dependente, considerando-se que esta é determinada exclusivamente por processos sociais e políticos, e não tecnológicos (Simões, 1995, 2005, 2006). As tecnologias são analisadas como criações postas ao serviço de elites 
poderosas para aumentarem o seu poder e dominação social. A hegemonia masculina nas sociedades contemporâneas contribuiria para que as escolhas sociais, a criação e o design das tecnologias - de onde as mulheres estariam arredadas - visassem a manutenção ou reforço da posição subalterna e dominada das mulheres, não só no campo tecnológico, como também no campo social mais lato.

Na perspectiva que Simões $(1995,2005,2006)$ designa de condicionamento recíproco - a que consideramos conter maior valor heurístico para a investigação, por não subscrever determinismos e por reconhecer a interinfluência entre estrutura e acção -, parte-se da rejeição de uma relação unidirecional entre tecnologia e sociedade em qualquer dos sentidos, o que implica que se abandonem as relações monocausais entre ambas e a preocupação de se determinar se é a tecnologia ou a sociedade que tem prioridade causal.

11 Ao considerar-se que a tecnologia é um processo social, ter-se-á em conta que é criada e adoptada (ou não) pela acção humana, o que implica, como aponta a autora, que não só a escolha, a criação, o design e o desenvolvimento das tecnologias, como também as suas utilizações abarcarão um leque mais alargado de factores sociais do que o usado nas perspectivas teóricas essencialistas. É certo que a tecnologia tem origens sociais e que a sua moldagem é conseguida, em grande parte, através da intervenção de grupos de interesse que exercem uma influência decisiva no seu desenvolvimento (Lyon, 1992; Burns e Flam, 2000); mas outros factores sociais moldam as tecnologias desde a sua criação, passando pelo seu desenvolvimento e incluindo o seu uso. É incontornável ter em conta, na análise, as tendências das sociedades capitalistas actuais, as quais poderão mesmo ser ampliadas pelas novas tecnologias (nomeadamente, a posição subalterna das mulheres numa sociedade ainda com forte pendor patriarcal), assim como os valores, as desigualdades sociais e de poder e os contextos sociais, políticos e culturais (Fischer, 1985; Lyon, 1992; Simões, 1995, 2005).

Contudo, na perspectiva teórica do condicionamento recíproco, como a própria designação sugere, não se subestima o condicionamento tecnológico: cada artefacto tecnológico pode condicionar a nossa acção numa direcção específica, abrindo determinados caminhos e fechando outros, embora de modo inter-relacionado com factores de escolha social. Ridgeway (2009) considera que o género é o primeiro quadro cultural a "marcar" a organização das relações sociais, e que sem o termos em conta não podemos compreender nem como a estrutura genderizada das sociedades contemporâneas resiste, nem como ela própria é alvo de mudança. A autora adopta a designação "regras de género" em vez de "estereótipos de género" e considera que aquelas não dizem respeito a crenças individuais, mas a crenças culturalmente hegemónicas, por duas razões. Primeiro, porque essas crenças estão profundamente enraizadas, nomeadamente nos media, nas políticas e nas leis e são um dado adquirido na maioria esmagadora das instituições. Segundo, porque elas estão presentes nos grupos dominantes da sociedade, aqueles que têm mais poder para moldar as instituições.

São os grupos dominantes da sociedade, hegemonicamente masculinos e portadores de estereótipos de género, que escolhem, criam e desenham os artefactos tecnológicos, podendo, então, afirmar-se, como adianta Henwood, (1993), que as relações de género moldam a tecnologia e que esta, por sua vez, condiciona as relações de género; no mesmo sentido, Wajcman (2000) afirma que género e tecnologia são mutuamente constitutivos.

A perspectiva do condicionamento recíproco tem como quadro de referência as teorias que se convencionou designar de síntese, ou seja, as que tentam superar a dualidade acção/estrutura, em particular a teoria dos sistemas de regras sociais, de Burns e Flam 
(2000). Para os autores, a actividade humana é, em grande parte, e nas suas mais variadas formas, governada por sistemas de regras (o que designam por estruturas sociais). Sendo a tecnologia uma componente fundamental da acção social, também é regulada por regras, regras essas que estabelecem, de modo mais implícito ou explícito, quem escolhe, quem cria, como, para quem, com que fins as diversas tecnologias.

Mas as estruturas não podem ser encaradas apenas como constrangimentos à acção social, elas oferecem também oportunidades para que os actores sociais possam agir, coordenadamente ou não, com o fim de defenderem os seus interesses e tomarem decisões. Ou seja, a acção envolve a possibilidade de os homens e/ou as mulheres serem capazes de "fazer de modo diferente" (idem: xii). Neste sentido, a tecnologia tanto pode contribuir para a reprodução de desigualdades, como para possibilitar novas práticas sociais.

\subsection{TIC e desigualdades de acesso}

16 A questão do acesso "tem sido analisada de modo muito simplista face à complexidade de questões que envolve, sendo o conceito muitas vezes mal operacionalizado e usado, quer nos trabalhos científicos, quer ao nível do discurso e das políticas para a SI" (Simões, 2005: 92-93).

17 Como refere a autora, o acesso não é uma questão neutra, importando analisar para quê, como, em que condições se desenvolve e quais os seus resultados. Simões (2005) acrescenta ainda que ter acesso às TIC é uma questão crucial, mas que as barreiras de acesso não são uma questão meramente física (ter ou não a possibilidade de aceder a um artefacto tecnológico). Esta perspectiva redutora tem levado a que se abordem apenas as questões do acesso dos indivíduos ao hardware, software e redes digitais e à necessidade de lhes fornecer treino adequado, sendo menosprezadas questões sociais, políticas e culturais que lhe estão associadas. Há ainda dois patamares distintos que têm sido confundidos, como se da mesma coisa se tratasse: a desigualdade do acesso às tecnologias (os incluídos ou excluídos das TIC) e a desigualdade que se pode desenvolver no pósacesso ao artefacto tecnológico (aí, de facto, os info-incluídos e os info-excluídos). 0 acesso físico às TIC é uma condição necessária para que se tenha acesso à informação disponível no ciberespaço, mas a posse ou o acesso a essas tecnologias não contraria per se a info-exclusão (Simões, 2005: 94).

18 A confusão entre esses dois patamares (excluídos ou incluídos quanto à posse das TIC e incluídos e excluídos da informação) tem ocultado uma questão central que se coloca às sociedades contemporâneas e que constitui uma outra dimensão do acesso às TIC: as desigualdades de uso (Simões, 2005). É neste sentido que se adopta a definição de desigualdade de informação apresentada por Van Dijk (2000), que contempla a desigualdade não só na posse de fontes de informação e comunicação, como também no uso dessas fontes.

19 Podemos enunciar várias dimensões do conceito de acesso propostas por Van Dijk (2000). A primeira barreira diz respeito ao acesso aos computadores e às redes digitais. A segunda, que o autor designa de "receio dos computadores", consiste em barreiras do foro subjectivo e emocional que levam as pessoas a considerarem como uma falha pessoal o manejo insatisfatório dessas tecnologias, evitando ou retardando, por esse facto, o contacto com as $\mathrm{TIC}^{1}$. A falta de competências, nas suas diversas facetas, constitui a terceira barreira a ultrapassar no acesso às TIC. Quanto mais reduzidas forem as 
competências, mais restrito será o uso dessas tecnologias. Competências diferenciadas "produzem e aprofundam as desigualdades de uso" (Simões, 2005: 100).

$\mathrm{O}$ acesso às TIC não significa apenas ter acesso ou possuir computadores, competências e software, mas também usufruir dos recursos do ciberespaço, entrando, pois, no campo das barreiras que se colocam ao uso, as mais difíceis de ultrapassar (Van Dijk, 2000).

21 Tanto as oportunidades, como os tipos de uso são também socialmente estratificados, nomeadamente em função do género, idade, condição socioeconómica. Simões (2005) considera que é simplista pensar-se que é suficiente ter acesso à informação. É central reflectir sobre o tipo de informação, a quantidade disponível e a sua qualidade, a sua relevância e fundamentação, a necessidade de ser facultada a tempo, num formato amigo do utilizador e em locais e a um custo que não coloquem barreiras ao acesso (Hague e Loader, 1999:11). É, por outro lado, necessário, segundo Simões (2005), que os utilizadores tenham os recursos cognitivos necessários para ter acesso a essa informação, para a organizar e utilizar e, ainda, ter tempo disponível para estar online, podendo também estabelecer-se, neste campo, desigualdades de uso significativas.

\subsection{Espaço doméstico: socialização e privacidade}

22 A casa constitui um importante elemento da estrutura social, funciona a partir da lógica da mediação, socializa ao mesmo tempo que isola, marca a diferença com o espaço público e, simultaneamente, reproduz os dispositivos sociais. Habitar o espaço doméstico não é um acto individual e passivo, bem pelo contrário, é uma relação recíproca entre o espaço e as pessoas que o habitam (Murillo, 1996).

23 A casa é um dos cenários diários da privacidade, a disposição dos seus espaços, os seus equipamentos e os usos que deles se fazem são conjuntamente contexto e efeito da socialização. $O$ estudo deste âmbito permite-nos captar os processos de reprodução social, nomeadamente das concepções específicas de género, assim como as permanências e mudanças nas dinâmicas familiares e nos estilos de vida.

24 Ao longo do século $\mathrm{XX}$, a casa tem-se configurado como o espaço da intimidade, da família, separado da esfera pública, particularmente da do trabalho, pois paulatinamente deixa de ser um espaço de produção de bens para se converter, cada vez mais, num espaço de reprodução, prestação de serviços e consumo. Simultaneamente, tem-se assistido a uma especialização interna deste espaço doméstico, designando a cada uma das divisões uma função, e a uma constante introdução de tecnologias no dito espaço. Para o caso português, a generalização de equipamentos nos agregados é recente e simultaneamente rápida, intensificando-se desde os anos 90 do século XX. 
Tabela 1. Agregados privados com equipamentos domésticos em Portugal (\%)

\begin{tabular}{|l|l|l|l|l|}
\hline & 1987 & 1995 & 2000 & 2005 \\
\hline Micro-ondas & $\mathrm{X}$ & 11.6 & 33.3 & 70.2 \\
\hline Frigorífico & 86 & 94.5 & 97.1 & 99 \\
\hline Aspirador & $\mathrm{X}$ & 58.5 & 67.3 & 79.9 \\
\hline Máquina de lavar roupa & 44 & 72,8 & 86,1 & 92,1 \\
\hline Máquina de lavar loiça & 6 & 12,8 & 17,1 & 34,7 \\
\hline Telefone fixo & 33 & 72 & 75,5 & 68,7 \\
\hline Telefone móvel & $\mathrm{X}$ & $\mathrm{X}$ & $\mathrm{X}$ & 83 \\
\hline Televisão & 83 & 95,6 & 97,9 & 98,9 \\
\hline TV cabo/satélite & $\mathrm{X}$ & 7,6 & 29,6 & 42,1 \\
\hline Leitor de CD & $\mathrm{X}$ & 18,2 & 38,4 & 53,4 \\
\hline Vídeo & $\mathrm{X}$ & 40,7 & 49,7 & $\mathrm{X}$ \\
\hline Leitor de DVD & $\mathrm{X}$ & $\mathrm{X}$ & $\mathrm{X}$ & 49.2 \\
\hline Computador & 3 & 10,1 & 21,9 & 43,9 \\
\hline
\end{tabular}

\section{VALOR INDISPONÍVEL}

FONTE: INE - INQUÉRITO AOS ORÇAMENTOS FAMILIARES (ATÉ 2000); INQUÉRITO ÀS DESPESAS DAS FAMÍLIAS (2005/2006); INE, INQUÉRITO ÀS CONDIÇÕES DE CONFORTO (1987).

Este processo de tecnificação do lar tem sido recentemente reforçado pela difusão das novas tecnologias da informação, da comunicação e das TIC e tem vindo a promover um debate sobre o seu impacto (entre outros factores) na configuração das fronteiras entre a esfera pública e a privada. Autores como Kaufman-Scarborough (2006) defendem que as TIC diluem as fronteiras espácio-temporais entre a casa e o trabalho. As propriedades de ubiquidade e a constante disponibilidade destas tecnologias permitem trazer o trabalho ao espaço doméstico e levar a casa ao trabalho. Porém, este efeito invasivo do trabalho no espaço privado é contestado por Green (2002) e Wajcman et al. (2008), aduzindo que sobretudo as mulheres estabelecem limites no uso destas tecnologias, que são empregadas prioritariamente para intensificar os contactos com a família e os amigos e para facilitar a microcoordenação familiar.

\section{Metodologia}

Os resultados aqui apresentados provêm de uma investigação em curso sobre os usos e representações do tempo e da tecnologia no contexto conjugal. 0 universo deste estudo é constituído por pessoas casadas (de facto ou de direito que convivam com o respectivo cônjuge) e residentes nos distritos de Braga e de Castelo Branco. A metodologia do projecto combina técnicas qualitativas e quantitativas de recolha de dados, tendo-se ainda recorrido a fontes secundárias de dados. 

amostragem não casual; realizou-se uma primeira estratificação segundo o distrito e a variável do INE de tipologia de áreas urbanas. Para a determinação dos sujeitos finais a inquirir, fixaram-se quotas por idade e sexo. Dado que se trata de uma amostra não representativa, os resultados da análise das tabelas de contingência têm um valor apenas indicativo. $O$ inquérito foi realizado mediante aplicação indirecta entre 16 e 31 de Janeiro de 2010 (Castelo Branco) e entre 5 e 20 de Fevereiro de 2010 (Braga) por uma equipa de inquiridores previamente formados para tal. Após a validação dos questionários, a amostra integrou 430 pessoas (211 homens e 219 mulheres), 212 para o distrito de Braga e 218 para o distrito de Castelo Branco. mulheres e um outro de homens pertencentes a casais onde ambos os cônjuges trabalham, metade dos participantes com pelo menos um filho co-residente com idade até 16 anos; um terceiro grupo composto por mulheres inactivas e desempregadas mas com o cônjuge empregado, metade com pelo menos um filho até 16 anos a residir no agregado; e, finalmente, um grupo de homens com características simétricas ao grupo três, isto é homens desempregados ou inactivos cujas mulheres têm emprego.

Finalmente, levaram-se a cabo 22 entrevistas individuais semi-estruturadas a ambos os membros do casal. A amostra das entrevistas foi construída segundo modelo de casos múltiplos por contraste; é composta por onze casais onde ambos trabalham; com idades entre os 25 e os 45 anos e diferentes níveis de estudos, seis deles com filhos co-residentes e cinco sem filhos.

31 A partir das transcrições integrais dos grupos de discussão e das entrevistas, foram construídas sinopses, ou sínteses das grandes temáticas, como forma de organizar a análise de discurso (Guerra, 2006).

\section{Uma posse massificada mas um uso crescentemente genderizado: a televisão e o telemóvel}

O uso das televisões tradicionais e das primeiras gerações de telemóveis tinha um padrão pouco genderizado. Qualquer uma destas tecnologias tem vindo a complexificar-se e a adquirir mais funcionalidades, o que poderá vir a tornar o seu uso mais genderizado.

33 A televisão é, sem dúvida, a tecnologia mais universalizada e, ao mesmo tempo, mais personalizada entre os equipamentos de lazer $^{2}$. A esmagadora maioria das famílias da nossa amostra (88\%) possui mais de um aparelho de televisão e vêem-na diariamente, sendo que um terço possui duas e quase outro terço três televisões. Tal proliferação de aparelhos corresponde, por um lado, a um uso mais individualizado por parte dos distintos membros da família e, por outro, à presença dos filhos. Os aparelhos estão localizados em diferentes divisões (nomeadamente cozinha, sala e quarto), permitindo uma particularização no seu uso. Neste sentido, é ilustrativo que entre os agregados onde 
apenas mora o casal ${ }^{3}, 40 \%$ tenham duas televisões e outros $40 \%$ três ou mais. No entanto, quando este valor se eleva para três ou mais televisões, o mesmo está relacionado com a presença de filhos nos agregados.

Os pais cedem às exigências dos filhos para ter TV nos quartos e o seu baixo custo contribui para a sua multiplicação nas famílias, evitando assim a contínua negociação em relação aos programas que se vê, para além de facilitar o cuidado dos filhos. Contudo, ver televisão em família à hora do jantar e ao serão faz parte dos rituais das famílias.

Mas a maior parte das vezes tenho eu que me chatear, porque, por exemplo, chegamos todos a casa, eu vou fazer o jantar, jantamos em casa. Temos este hábito terrível, um vai ver televisão para o quarto, outro vai ver televisão para a sala, o outro vai para o computador, e eu vou para a cozinha fazer o jantar, e fico danada de cada vez que isto acontece, e depois, claro, tenho que esparvoar um bocadinho e depois toda a gente vai ajudar a fazer o jantar.

(Grupo I, mulheres empregadas)

A experiência das mulheres não remete tanto para ver, mas sim para ouvir a televisão, e esta prática ocorre em simultâneo com a realização dos trabalhos domésticos (nomeadamente passar a ferro, cozinhar ou tratar das crianças), pelo que costuma decorrer mais na cozinha.

- Tem uma televisão? Tem várias?

- Sim, sim. Tenho várias.

- E estão onde?

- Na cozinha, na sala e no quarto dos miúdos (risos) a minha da cozinha está sempre ligada. Às vezes não olho para ela, mas estou a ouvi-la.

(Mulher, 41 anos, 9. ano, operária têxtil, dois filhos)

O facto de as mulheres serem as principais responsáveis pelo cuidado das crianças condiciona também o seu consumo televisivo (particularmente "o quando e o que" vêem); tanto nos grupos de foco como nas entrevistas, as mães referem "sacrificar gostosamente" as suas preferências televisivas ou o seu tempo livre para acompanhar a programação infantil com os filhos":

- Para mim, tempo livre é realmente só para mim, é fazer qualquer coisa que só o lucro, digamos, seria só para mim, (pensativa) contudo não é isso que se verifica não é, mas temos de... o tempo livre quase que encará-lo como que para todos, preferia estar no sofá até a ver um programa, mas tenho que me limitar a estar no sofá a ver uma banda desenhada, cá está, o tempo livre.

- Porquê? Por causa do seu filho?

- Exactamente.

(Mulher, 36 anos, licenciada, técnica superior, um filho)

37 Por seu lado, os homens tendem a despender menos tempo a ver televisão quando o fazem, fazem-no de forma exclusiva, ou seja, sem combinar com outras actividades. Já quanto aos conteúdos que se vê, estes diferem consideravelmente, sendo que cada vez mais os programadores televisivos apostam nos conteúdos em função de um público-alvo definido principalmente pela idade e género (a SIC Mulher é um bom exemplo deste tipo de programação estratégica).

Embora a posse do telemóvel não apresente diferenças de género, o mesmo não se pode dizer em relação ao seu uso, onde essas diferenças se registam também em termos da utilização das diversas funcionalidades. Em relação ao uso comunicativo ou primário do telemóvel, evidencia-se a influência dos papéis de género ${ }^{6}$. Assim, as mulheres referem usar mais o telemóvel para contactar com amigos e familiares ( $72,8 \%$ face a $49,3 \%$ dos homens, e de entre os familiares destacam os filhos, com $22,2 \%$ face a $9,7 \%$ dos homens). 
No entanto, os homens dizem usar o telemóvel principalmente para o trabalho (25\% face a $6 \%$ das mulheres) ou para estarem contactáveis ${ }^{7}$.

39 As mulheres entrevistadas valorizam a possibilidade, conferida pelo telemóvel, de relação constante com o mundo, como se fosse um "cordão umbilical" que as une aos filhos, cônjuge, amigos, etc., o qual permite o prolongamento dos cuidados. Neste sentido, o telemóvel torna-se uma ferramenta valiosa para manter o contacto entre os membros da família no quotidiano, no sentido de estar presente na ausência, de estar sempre contactável em caso de necessidade para prestar ajuda. Principalmente as mulheres valorizam a importância do uso do telemóvel como ferramenta para a microcoordenação das actividades quotidianas das famílias, permitindo uma gestão mais flexível dos tempos, continuando, assim, o papel de coordenação nas suas mãos, o que vai ao encontro do apontado por Ling (2006). Importa, contudo, ter em conta que o telemóvel introduz mudanças no modo como as tarefas domésticas são coordenadas, ou seja, essa coordenação passa a ser realizada de um modo que não seria possível sem aquele artefacto tecnológico, o que ilustra o papel simultaneamente condicionador $\mathrm{e}$ possibilitador da tecnologia.

No caso dos trabalhadores por conta própria, na nossa amostra maioritariamente homens, o telemóvel é uma ferramenta de trabalho imprescindível, torna-se quase um meio de vida. Uma posição igualmente relevante ocupa o telemóvel na vida das mulheres que realizam trabalhos na economia informal (fazer salgados para fora, limpezas, etc.) e que percepcionam o telemóvel como um instrumento que lhes facilita novas oportunidades de trabalho. Também nestes dois casos é visível o modo como a tecnologia, neste caso o telemóvel, participa na construção de novas oportunidades de trabalho e na sua organização.

41 A par de uma apreciação geral muito positiva do telemóvel ${ }^{8}$, surge, entre os homens e as mulheres sem filhos, uma crítica relativa à permanente disponibilidade que exige e à intromissão que acarreta na sua vida privada. Esta percepção ambivalente do telemóvel como facilitador e como dispositivo de controlo (por parte do meio social) leva-os a reivindicar a conveniência de edificar algumas barreiras no seu uso (não responder ou desligar):

E - E outra coisa do telemóvel é que acho que retirou muita privacidade, acho que as pessoas sentem-se quase obrigadas a atender o telefone desde que esteja ligado, as pessoas, quem está a ligar acha que a pessoa deve atender, e portanto isso também tira um bocado de privacidade.

H - Em relação ao telemóvel já faço de propósito, às vezes desligo, às vezes deixo em casa, e o prazer de ninguém saber onde eu estou [...].

(Grupo I, mulheres empregadas)

[...] porque hoje em dia toda a gente sabe onde nós estamos, o que é que nós fazemos, o que é que não fazemos, acho que isso de certa forma torna-se uma invasão da nossa própria privacidade ou do nosso próprio espaço...

(Grupo IV, homens empregados)

Não obstante essa crítica relativa ao potencial de intrusão, quando perguntamos se atendem chamadas de trabalho no telemóvel quando estão em casa e se atendem chamadas de familiares no trabalho, tanto os homens como as mulheres respondem que atendem sempre. Num contexto de crise de emprego crónica, que faz do trabalho remunerado uma ventura a preservar, a possibilidade de obviar as chamadas de trabalho para manter as fronteiras espácio-temporais entre trabalho e família é um luxo só ao alcance daqueles que têm uma posição segura. 


\section{Uma posse crescentemente massificada mas um uso genderizado: o computador e a Internet}

43 Os dados do nosso inquérito apontam para uma introdução elevada, nas famílias, do computador (72\%) e da Internet (64\%) ${ }^{9}$. Mas esta expansão evidencia também padrões diferenciados de acesso, em função da idade, do género, da classe socioprofissional ${ }^{10} \mathrm{e}$ da escolaridade, entre outros.

No entanto, como referem Van Dijk (2000) e Simões (2005), o acesso, entendido exclusivamente como posse, não garante o seu uso, nem garante um uso aprofundado de todas as suas funcionalidades. A posse, por exemplo, do computador com ligação à Internet é bastante comum nas classes baixas, devido, em parte, ao "efeito" Magalhães ${ }^{11}$. Entre os operários e assalariados executantes, a posse do computador atinge $65 \%$ e a da Internet 55\%; mais relevante é a razão pela qual referem ter computador com ligação à Internet: ser necessário para os filhos. Esta é a principal razão enunciada por $60 \%$ de operários industriais e assalariados agrícolas, contra $30 \%$ dos empresários, dirigentes, profissionais liberais, profissionais técnicos e de enquadramento. Estes aludem à actividade profissional (33\%), aos filhos e à obtenção de informação (20\%) como principais razões. Registam-se, ainda, desigualdades na utilização dos referidos artefactos tecnológicos ao nível dos pais: em $50 \%$ dos agregados de operários e assalariados nenhum dos membros do casal usa Internet e em $30 \%$ apenas é usada por um dos cônjuges ${ }^{12}$. Nestes agregados, o computador e/ou a Internet são entendidos como um novo e necessário material para os trabalhos escolares, tal como os livros e os lápis, e consideram-se de uso exclusivo dos filhos. Aspecto que evidencia, como se referiu, que a posse das TIC é uma condição necessária, mas não suficiente, para se ter acesso à informação disponível no ciberespaço: a posse (ou acesso físico às TIC) não contraria per se a info-exclusão (Simões, 2005).

As diferenças de género são uma constante no uso da Internet a partir de casa: os homens usam mais a Internet em tempo e frequência de conexão. 0 nível de estudos, a idade, a classe socioprofissional e a presença de filhos no agregado influenciam o uso sem mitigar totalmente as diferenças de género. Assim, apenas observamos elevadas percentagens de utilização da Internet a partir de casa (acima de 70\%) sem diferenças entre géneros nos mais novos, com estudos secundários ou superiores e com uma posição média-alta na escala profissional. Em relação ao tempo despendido no uso da Internet em casa, as diferenças por género a favor dos homens persistem em todas as variáveis referidas, com a excepção de algumas categorias socioprofissionais (técnicos intermédios, profissionais e pessoal administrativo), nas quais as mulheres registam tempos semelhantes aos dos homens (mais de uma hora diária).

É de realçar o efeito dos filhos, pois este actua no sentido de reduzir o uso da Internet em casa: $79 \%$ de entre os agregados sem filhos dizem usá-la, face a $49 \%$ entre as famílias com filhos. A presença de filhos no agregado limita mais as mulheres do que os homens no uso da Internet em casa ( $41 \%$ e $58 \%$, respectivamente), diferenças de género que se alargam quando os filhos são menores de 6 anos (62\% das mulheres com filhos menores de 6 anos usam a Internet desde casa face a $88 \%$ de homens em situação análoga). Verifica-se a mesma tendência em termos de tempo médio diário de uso da Internet a partir de casa: 
80\% das mulheres com filhos menores de 6 anos despendem diariamente menos de uma hora comparativamente aos $40 \%$ dos homens na mesma situação:

E - Como é que são os usos do computador e da Internet, são mais para si, mais para o seu cônjuge, é igual?

M - É igual, embora ele, provavelmente, use mais, porque depois ele adere mais a alguns jogos cibernéticos e, provavelmente, passa mais tempo, digamos, no computador.

E - Esses jogos passam-se na altura em que você está a fazer...?

M - Sim, no fim do jantar, normalmente é no fim do jantar. Por norma, enquanto toma conta da criança, estou a organizar ou a limpar a cozinha ou no final alguma loiça.

(Mulher, 36 anos, licenciada, técnica superior, um filho)

Se atendermos ao tempo despendido na realização das tarefas domésticas por sexo, verificamos uma forte limitação por parte das mulheres no tempo disponível para o uso da Internet. Em média, os homens despendem sete horas semanais nas ditas tarefas contra as vinte horas despendidas pelas mulheres. Se tivermos em conta o tempo de cuidado de filhos e dependentes, as diferenças são ainda mais marcantes (12 horas face a 38 horas). Constantemente, as mulheres duplicam, no mínimo, os tempos de trabalho doméstico dos homens. $\mathrm{O}$ cuidado dos filhos e os trabalhos domésticos balizam de forma acentuada o acesso das mulheres a esta tecnologia e moldam o uso que dela fazem ${ }^{13}$.

As mulheres entrevistadas conectam-se à Internet com menos frequência, dedicam-lhe menos tempo e, quando a utilizam, fazem-no com objectivos diferentes em relação aos dos homens. É particularmente no contexto doméstico que se evidencia o uso genderizado, tanto na quantidade de tempo online como na finalidade da navegação. Os interesses femininos na rede estão orientados para a procura de informações para a família (receitas, saúde, etc.) e para a comunicação com as suas redes sociais (mail, chat, etc.), enquanto os homens praticam um uso mais instrumental (questões de trabalho, downloads de programas, leitura de imprensa, etc.) e orientado para o lazer (downloads de jogos, música, hobbies, etc.), tendências já avançadas por Kennedy et al. (2003) e Dholakia (2004).

Em relação aos efeitos das TIC, nomeadamente da Internet e do computador na erosão das fronteiras entre o espaço doméstico e o do trabalho, os nossos dados apontam para uma provável intensificação do trabalho em casa por parte daqueles que já antes da introdução destas tecnologias no âmbito doméstico levavam trabalho para realizar no seu domicílio. Como referenciam Wajcman, Bittman et al. (2008), a extensão do trabalho remunerado na esfera familiar tem mais a ver com as características do emprego do que com a posse no agregado de tecnologias da informação e comunicação. Professores, empresários e outras profissões que têm autonomia para desenvolver o seu trabalho fora dos horários laborais são os que mais utilizam estas tecnologias para trabalhar em casa. No entanto, as mulheres que possuem computador e as competências para usá-lo mostram-se mais relutantes do que os homens em levar trabalho para casa, não desejam que a esfera privada seja invadida pelo trabalho:

[...] sei as vantagens, não conseguiria viver, aliás no trabalho quando falham os computadores ou falha o servidor, parecemos umas baratas tontas... (as participantes D e E concordam acenando com a cabeça) e agora o que é que fazemos? Uma carta... e fazemos à mão? As coisas mais básicas, portanto sou viciada em tecnologia, trabalho o dia todo agarrada a um computador, no entanto lá está, tenho computador em casa, e chego a casa e não tenho coragem de o ligar, porque já passei o dia todo no computador e... Estou farta, e tenho em excesso, na 
realidade.

(Grupo I, mulheres empregadas) pessoal que fazem das mesmas. O grau de domínio liga-se às funcionalidades que consideram necessárias na sua vida quotidiana, assumindo que é impossível ter um conhecimento e controlo total destas tecnologias. Adopta-se, portanto, uma perspectiva muito utilitarista e pragmática e, na medida em que conseguem servir-se delas quotidianamente, consideram-nas fáceis:

Eu não sou... Por exemplo a nível de computadores não sou uma pessoa que passa muitas horas, eu uso aquele... eu acho que não há nada que eu explore muito, eu uso o telemóvel consoante as necessidades que tenho, não, não, se eu não uso a máquina fotográfica... por acaso tenho mas não, não perco muito tempo com isso, o computador pode ter lá mil programas mas se eu só trabalho com Word e Excel, não tenho, por norma, de andar a ver como funcionam todos os outros a não ser que haja essa necessidade...

(Mulher, 30 anos, licenciada, técnica superior, um filho)

Porém, uma constante na autopercepção do grau de domínio das TIC é a maior dificuldade expressa pelas mulheres entrevistadas e a menor dificuldade avançada pelos homens.

\section{Reflexões finais}

52 Já muito se investigou sobre a relação entre a tecnologia e o género no âmbito do espaço público. Aqui procurou-se mapear e compreender essa relação no âmbito do espaço doméstico, partindo de tecnologias (de informação, da comunicação e TIC) que não são tipicamente conotadas com os papéis de género, pelo que aparentemente menos genderizadas. $\mathrm{O}$ facto de se estudarem casais no espaço doméstico permitiu captar o aspecto relacional num espaço que é tanto individual, como socialmente significativo, e no qual as relações de género se tornam menos publicamente mediadas.

O acesso, nas suas diversas dimensões, às tecnologias no espaço doméstico continua a ser influenciado pelo modelo geral tradicional de divisão sexual do trabalho. Embora mais recentemente tenham surgido mudanças neste padrão (uma maior participação dos homens), o espaço e o trabalho doméstico continuam a ser, na maioria dos casais, uma responsabilidade predominantemente feminina. Tais mudanças estão associadas, entre outros factores, ao aumento da participação das mulheres no mercado de trabalho, particularmente quando trabalham a tempo inteiro (Gershuny, 1994). A presença das mulheres na esfera pública, contudo, parece ser uma condição necessária mas não suficiente para alcançar uma distribuição mais igualitária do trabalho doméstico (Perista, 2010).

54 A questão que se coloca na relação entre espaço doméstico e tecnologia é que a apropriação e a construção de sentido das tecnologias neste espaço estão marcadas pelas relações de género. Assim, por exemplo, podemos encontrar mulheres com competências de uso das TIC no espaço público, mas que as usam escassamente no espaço doméstico, como resultado das restrições impostas pelo desempenho do seu papel de género, nomeadamente no cuidado das crianças, ou ainda da sua escolha em não as usar.

Castells (1998) chamou a atenção para a crescente estratificação social dos utilizadores das TIC, em que a escolha do produto multimédia será feita em função do género e das habilitações literárias, entre outros aspectos. A investigação em curso permitiu-nos 
constatar que as diferenças de género não se colocam tanto ao nível da escolha, ou mesmo da aquisição das tecnologias, dada a sua crescente massificação, mas ao nível dos usos, dos tempos de uso, das competências de uso e dos tipos de uso. Comparativamente aos homens, as mulheres revelam uma auto-avaliação inferior das suas competências tecnológicas, menos tempo de utilização das TIC, bem como uma utilização que se traduz em menos frequência e com interesses diferenciados.

O uso que homens e mulheres fazem da tecnologia parece ser condicionado tanto pelas diferenças ainda prevalecentes nos papéis de género, como pelo modo como essas diferenças e esses papéis são entendidos por cada um deles. Não se trata apenas, nem sobretudo, do facto de as mulheres utilizarem menos estas tecnologias em análise, mas sim e sobretudo de as utilizarem de modos diferenciados, estando estes intimamente relacionados com os processos de reprodução social, nomeadamente das concepções específicas de género, que ocorrem no âmbito do espaço doméstico.

Não obstante estas diferenças de género se atenuarem perante a posse de habilitações literárias superiores, quando são as mulheres a detê-las, estas optam por não as usar ou, de novo, por as usar de modo diferenciado.

\section{BIBLIOGRAFIA}

BURNS, Tom; FLAM, Helena (2000), Sistemas de Regras Sociais. Teorias e aplicações, Oeiras, Celta.

CASTELLS, Manuel (1998), The Rise of the Network Society, vol. 1, Oxford, Blackwell.

DHOLAKIA, Ruby; DHOLAKIA, Nikhilesh; KSHETRI, Nir (2004), "Gender and Internet usage”, in Hossein Bidgoli (ed.), The Internet Encyclopedia, New York, Wiley, 12-22.

FISCHER, Claude (1985), "Studying technology and social life”, in Manuel Castells (ed.), High Technology, Space and Society, Urban Affairs Annual Reviews (28), Beverly Hills, Sage, 284-301.

FISHER, Kimberly; EGERTON, Muriel; GERSHUNY, Jonathan; ROBINSON, John P. (2006), “Gender convergence in the American heritage time use study (AHTUS)", ISER working Papers, 25, [Online] disponível em: http://www.iser.essex.ac.uk/files/iser_working_papers/, [consultado em: 15-11-2009].

GERSHUNY, Jonathan; GODWIN, Michael; JONES, Sally (1994), "The domestic labour revolution: a process of lagged adaptation?", in Michael Anderson, Frank Bechhofer \& Jonathan Gershuny (eds.), The Social and Political Economy of the Household, Oxford, Oxford University Press, 151-197.

GREEN, Nicola (2002), "On the move: Technology, mobility, and the mediation of social time and space”, The Information Society 18 (4), 281-92.

GUERRA, Isabel (2006), Pesquisa Qualitativa e Análise de Conteúdo, Estoril, Principia.

HENWOOD, Flis (1993), "Establishing gender perspectives on information technology: Problems, issues and opportunities" in Eileen Green, Jenny Owen, Den Pain (eds.), Gendered by Design? Information technology and office systems, London, Taylor \& Francis, 31-52. 
INE/UMIC (2010), Inquérito à Utilização de Tecnologias da Informação e da Comunicação pelas Famílias 2010 [Online] disponível em: http://www.umic.pt, [consultado em: 5-12-2010].

INE/UMIC (2008) Inquérito à Utilização das Tecnologias da Informação e da Comunicação pelas Famílias 2002-2008 [Online] disponível em http://www.umic.pt, [consultado em: 3-11-2010].

KAUFMAN-SCARBOROUGH, Carol (2006), “Time use and the impact of technology: Examining workspaces in the home", Time \& Society, 15 (1), 57-80.

KENNEDY, Tracy; WELLMAN, Barry; KLEMENT, Kristine (2003), “Gendering the digital divide”, IT \& Society, 1 (5), 72-96.

LING, Rich (2006), "Flexible coordination in the Nomos: Stress, emotional maintenance and coordination via the mobile telephone in intact families", in Anandam Kavoori \& Noah Arceneaux (eds.), The Cell Phone Reader: Essays in social transformation, NY, Peter Lang, 61-84. LYON, David (1992), A Sociedade da Informação, Oeiras, Celta.

MACHADO, Fernando Luís; COSTA, António Firmino da; MAURITTI, Rosário; MARTINS, Susana da Cruz; CASANOVA, José Luís; ALMEIDA, João Ferreira de (2003), “Classes sociais e estudantes universitários: Origens, oportunidades e orientações”, Revista Crítica de Ciências Sociais, 66, 45-80.

MATTINGLY, Marybeth J.; BIANCHI, Suzanne (2003), “Gender differ ences in the quantity and quality of free time: The U.S. experience". Social Forces, 81 (3), 999-1030.

MURILLO, Soledad (1996), El mito de la vida privada: de la entrega al tiempo propio, Madrid, Siglo XXI Editores.

OBERCOM (2008), A sociedade em rede em Portugal: Apropriações do telemóvel na sociedade em rede [Online] disponível em: http://www.obercom.pt [consultado em: 27-10-2009].

PERISTA, Heloísa (2010), "Mulheres, homens e usos do tempo: Quinze anos após a Plataforma de Acção de Pequim, onde estamos, em Portugal?", Revista de Estudos Demográficos, 47, 47-64.

RIDGEWAY, Cecilia (2009), "framed before we know it: How gender shapes social relations", Gender \& Society, 23 (2), 145-160.

SAYER, Liana (2005) “gender, time and inequality: Trends in women's and men's paid work, unpaid work and free time", Social Forces, 84 (1), 285-303.

SIMÕES, Maria João (2006), “Contributos para uma sociologia da tecnologia”, Configurações, 2, 75-88.

SIMÕES, Maria João (2005), Política e Tecnologia. Tecnologias da Informação e da Comunicação e participação política em Portugal, Oeiras, Celta.

SIMÕES, Maria. João (1995) “Mudança tecnológica e mudança social: O caso das Tecnologias da Informação", PACP (Relatório científico), Covilhã, UBI, (policopiado).

VAN DIJK, Jan (2000), “Widening information gaps and policies of prevention”, in Kenneth L. Hacker \& Jan Van Dijk (eds.), Digital Democracy, London, Sage, 166-183.

WAJCMAN, Judy (2000), "Reflections on gender and technology studies: In what state is the art?", Social Studies of Science, 30 (3), 447-64.

WAJCMAN, Judy; BITTMAN, Michael; BROWN, Jude (2008), "Families without borders: Mobile phones, connectedness and work-home divisions", Sociology, 42 (4), 635-652.

WRIGHT, Erik Olin (2008), “Institutions promoting gender egalitarian families", Politics \& Society, 36 (3), 311-312. 


\section{NOTAS}

1. Aspecto que tenderá a decrescer com a progressiva generalização do uso das TIC, mas que implica medidas adequadas para que possa mais rapidamente ser superado.

2. Segundo dados do inquérito à ocupação do tempo em Portugal (INE, 2001), três quartos do tempo destinado ao lazer é despendido a ver televisão ( 2 horas e 20 minutos, em média, por dia), nomeadamente no horário nocturno (a partir das 20h40). Segundo o serviço de Media-Monitor da Marktest para o ano de 2010, a média de tempo despendido a ver televisão por espectador foi de 3 horas e 39 minutos diários. Estes valores põem em evidência o peso que esta prática tem na vida dos portugueses.

3. Seja porque os filhos já não residem com o casal ou porque não existem filhos.

4. Verifica-se o que vários autores têm referido em relação à caracterização do tempo livre das mães: é um tempo fragmentado que se desfruta com a ausência de outros adultos e que tende a confundir-se com as responsabilidades parentais (Mattingly e Bianchi, 2003).

5. Segundo o Anuário Média e Publicidade da Marktest (2009), as mulheres tendem a ver mais televisão do que os homens (56,2\% face a $43,8 \%$ respectivamente, no respeitante à audiência das televisões generalistas).

6. Segundo o Obercom (2008), o principal uso deste equipamento é o comunicativo: ligar e receber chamadas. $\mathrm{O}$ aproveitamento das novas e crescentes funcionalidades associadas aos telemóveis, tais como Internet, GPS, etc., depende, nomeadamente, da idade: jovens e adolescentes são mais propensos ao uso destas funcionalidades secundárias.

7. Estas diferenças no uso por género mantêm-se mesmo quando cruzadas com outra variável como a idade, nível de estudos, classe socioprofissional e tempo de trabalho. Apenas no caso dos casais onde só trabalha a mulher, estas referem usar um pouco mais o telemóvel para o trabalho (19\%), valor que fica abaixo dos $26 \%$ referenciados por homens na mesma situação.

8. De modo geral, as tecnologias são percepcionadas pelos entrevistados como facilitadoras das suas vidas quotidianas, elementos de progresso social e pessoal, instrumentos que aumentam o leque de oportunidades, sendo, de facto e em suma, muito positivamente conotadas.

9. Segundo os dados do INE/UMIC, Inquérito à Utilização das Tecnologias da Informação e da Comunicação pelas Famílias 2002-2008, o computador e a ligação à Internet têm experimentado uma forte difusão em Portugal, 50\% e 46\%, respectivamente, duplicando ou triplicando a sua presença nos agregados portugueses em menos de uma década.

10. Nesta investigação a variável classe social foi operacionalizada segundo a matriz de construção individual e familiar proposta por Machado et al. (2003). Falamos em classe socioprofissional porque a dita variável, como referem os autores, está construída a partir dos indicadores "profissão" (Classificação Nacional de Profissões) e "situação na profissão".

11. O Magalhães é um computador concebido para crianças que faz parte do Programa e.escola. Este projecto visa promover o acesso à Sociedade da Informação e fomentar a info-inclusão, através da disponibilização de computadores portáteis e ligações à Internet de banda larga, em condições economicamente vantajosas, aos alunos e professores dos ensinos básico e secundário.

12. Acrescente-se que $80 \%$ dos que têm Internet por causa dos filhos não usam Internet a partir de casa e $90 \%$ dos que não usam Internet em casa não sabem utilizá-la.

13. Como também referem Kennedy et al. (2003), os papéis tradicionais de género influenciam o acesso à Internet a partir de casa, inclusive no grupo das mulheres usuárias de Internet. 


\section{RESUMOS}

Partindo de um quadro teórico que reconhece as relações de reciprocidade entre tecnologia e sociedade como condicionantes da mudança social, o presente artigo procura compreender, a partir das análises providenciadas por uma investigação em curso, as complexas relações entre as tecnologias da informação, as tecnologias da comunicação e as TIC e o género no espaço doméstico, chamando-se particular atenção para o carácter genderizado do uso da tecnologia, o qual denota o ainda prevalecente padrão da divisão dos papéis de género e a consequente permanência de representações tradicionais sobre a divisão do trabalho doméstico.

Starting from a theoretical framework that recognizes the reciprocal relationships between technology and society as drivers of social change, this article aims to understand, from the analysis provided by an ongoing research, the complex relationships between information technology, communication technology, ICT and the gender at home, giving special emphasis to the gendered use of technology. This use denotes the still prevailing pattern of the gender roles division and the consequent persistence of traditional representations of the housework division.

À partir d'un encadrement théorique qui perçoit les relations de réciprocité entre technologie et société en tant que moteurs du changement social, le présent article cherche à comprendre, depuis les analyses obtenues d'une recherche en cours, les relations complexes entre les technologies de l'information, de la communication et TIC et genre dans l'espace domestique, mettant l'accent sur le caractère genré de l'utilisation de la technologie, laquelle dénonce un modèle de division des rôles de genre encore en vigueur et la conséquente persistance des representations traditionnelles sur la division du travail domestique.

ÍNDICE

Palavras-chave: acesso, tecnologia, género, espaço doméstico

Keywords: access, technology, gender, domestic space

Mots-clés: voies d'accès, technologie, genre, espace domestique

\section{AUTORES}

\section{MARIA JOÃO SIMÕES}

Professora Auxiliar da UBI, investigadora efectiva do CICS da UM, mariajoaosimoes@sapo.pt

\section{SOLEDAD LAS HERAS}

Mestre em Sociologia; investigadora do UBI_CES, soledad@ubi.pt

\section{AMÉLIA AUGUSTO}

Professora Auxiliar da UBI, investigadora do CIES, aaugusto@ubi.pt. Os resultados apresentados provêm do projecto em curso "Tempo e tecnologia: uma abordagem de género para o contexto 
português", financiado por Fundos FEDER através do Programa Operacional Factores de Competitividade - COMPETE e por Fundos Nacionais através da FCT - Fundação para a Ciência e a Tecnologia (PIHM/GC/0037/2008). Equipa do projecto: Maria Johanna Schouten (investigadora responsável), Emília Araújo, Helena Sousa, Lia Lourenço e as autoras deste artigo. 